\title{
Erythrocyte arginase activity as an indicator of lead exposure
}

\author{
K FUKUMOTO, ${ }^{1}$ I KARAI, ${ }^{2}$ Y NISHIKAWA,${ }^{3}$ AND S HORIGUCHI ${ }^{2}$
}

From the Osaka Prefectural Institute of Occupational Health, ${ }^{1}$ Osaka, 540, the Department of Preventive Medicine and Public Health, ${ }^{2}$ Osaka City University Medical School, Osaka, 545, and the Department of Clinical Chemistry, ${ }^{3}$ Osaka Prefectural Hospital, Osaka, 558, Japan

ABSTRACT A semi-automated method has been developed for the determination of the arginase activity of erythrocytes using dried blood spots, which are easy to prepare on site in a factory for later laboratory analysis. The mean arginase activity of erythrocytes in 49 men occupationally exposed to lead was $62 \cdot 9 \mathrm{IU} / \mathrm{g} \cdot \mathrm{Hb}(\mathrm{SD}, 14 \cdot 4 \mathrm{IU} / \mathrm{g} \cdot \mathrm{Hb})$; in $45 \mathrm{men}$ not exposed to lead the mean was $44.6 \mathrm{IU} / \mathrm{g} \cdot \mathrm{Hb}(\mathrm{SD}, 11.6 \mathrm{IU} / \mathrm{g} \cdot \mathrm{Hb})$. A significantly higher mean arginase activity was found in the specimens from lead-exposed workers $(p<0.001)$. The correlation coefficient between blood lead and erythrocyte arginase was $r=0.67(p<0.001)$. The degree of correlation between blood lead and lead indicators including arginase was $r=0.75$ for urine $\delta$-aminolaevulinic acid, $r=0.67$ for erythrocyte arginase, $r=0.66$ for urine lead, and $r=0.63$ for coproporphyrin. Erythrocyte arginase showed no significant correlation in the liver function tests, GOT, GPT, and albumin in serum. When $40 \mu \mathrm{g} / 100 \mathrm{~g}$ of blood lead concentration was fixed as the basic value and $56 \cdot 2 \mathrm{IU} / \mathrm{g} \cdot \mathrm{Hb}$ of erythrocyte arginase activity was set as the screening value in lead-exposed workers, the sensitivity and specificity of the arginase test were 0.96 and 0.65 , respectively. Thus the validity of the test was calculated to be $1 \cdot 61$. These results show that the arginase level of erythrocytes can be considered to be one of the significant indicators of occupational exposure to lead because it reflects well the dose-response relationship of lead in the human body. Our method allows rapid analysis of erythrocyte arginase and thus should be useful in screening for lead exposure.

Arginase (EC 3531) which catalyses the hydrolysis of arginine to ornithine and urea is present in the urea cycle. Arginase, an enzyme activated by a binary cation, ${ }^{1}$ is present mainly in liver, kidney, and erythrocytes in man. Familial hyperargininaemia is well known as a disorder of urea synthesis with erythrocyte arginase deficiency. ${ }^{23}$ Arginase activity in erythrocytes increases in pernicious anaemia and thalassaemia major ${ }^{4}$; serum arginase activity increases in liver diseases. ${ }^{6}{ }^{7} \mathrm{Chmielnicka}^{8}$ reported recently that serum arginase is an indicator of liver damage caused by exposure to lead, the effect of exposure to lead on erythrocyte arginase activity has not been fully discussed. In this study erythrocyte arginase, blood lead, and other lead indicators were analysed in lead-exposed and lead-unexposed workers. Using the suggestion by Zielhuis and Verberk $^{9}$ who have introduced the concept of validity

Received 12 October 1981

Accepted 4 June 1982 of biological tests in epidemiological toxicology, we studied the sensitivity (SE), specificity (SP), and validity (V) of the lead indicator tests, fixing the basic value of blood lead as $40 \mu \mathrm{g} / 100 \mathrm{~g}$. The screening value of arginase activity was set to show the maximum SE and V from the concept of a screening test. The SE and V of the arginase test are compared with those of other lead indicator tests and the usefulness of the arginase test as a lead indicator is discussed.

\section{Subjects}

Forty-nine male workers (aged 25-70, mean 46) exposed to lead in a scrap lead refining factory were studied. Forty-five workers (aged 26-56, mean 42) free from lead exposure in a well-equipped insecticide factory were studied as controls. A health questionnaire was submitted to both groups and clinical laboratory tests were performed before the experiment. Workers with abnormal liver function test results and endocrinological disorders were excluded. 
Samples of blood and urine were collected from each worker. For the erythrocyte arginase assay, three drops of heparinised blood were spotted on to a filter paper and allowed to dry at room temperature. Three discs ( $6 \mathrm{~mm}$ in diameter) of a sample, a blank, and a sample for $\mathrm{Hb}$ determination were punched from the dried blood spots with an office puncher.

\section{Methods}

\section{ASSAY OF ARGINASE ACTIVITY}

\section{Reagents}

Distilled water free of ammonium ion was used. Enzymes and coenzyme were purchased from Boehringer, Mannheim, FRG. All chemicals were of the highest purity commercially available.

Glycine buffer-Dissolve $7.51 \mathrm{~g}$ of glycine in distilled water, adjust the $\mathrm{pH}$ to $9 \cdot 50$ with sodium hydroxide $(1 \mathrm{~mol} / \mathrm{l})$, and dilute to one litre with distilled water.

Arginine solution-Dissolve $15.8 \mathrm{~g}$ of arginine monohydrochloride (Merck) in distilled water, adjust the $\mathrm{pH}$ to 9.50 with sodium hydroxide $(1 \mathrm{~mol} / \mathrm{l})$, and dilute to $100 \mathrm{ml}$ with distilled water.

$\mathrm{MnCl}_{2}$ solution-Dissolve $5 \mathrm{~g}$ of $\mathrm{MnCl}_{2} \cdot 4 \mathrm{H}_{2} \mathrm{O}$ in distilled water and dilute to $100 \mathrm{ml}$.

Perchloric acid-Dilute $3.6 \mathrm{ml}$ of $60 \% \mathrm{HClO}_{4}$ to $100 \mathrm{ml}$ with distilled water $(0.33 \mathrm{~mol} / \mathrm{l})$.

2-Oxoglutaric acid sodium salt in phosphate buffer-Dissolve $20.97 \mathrm{~g}$ of $\mathrm{Na}_{2} \mathrm{HPO}_{4} \cdot 12 \mathrm{H}_{2} \mathrm{O}, 1.18 \mathrm{~g}$ of $\mathrm{KH}_{2} \mathrm{PO}_{4}$ and $0.6 \mathrm{~g}$ of $\mathrm{NaOH}$ with distilled water, add $1.19 \mathrm{~g}$ of 2-oxoglutaric sodium salt, adjust the $\mathrm{pH}$ to $7 \cdot 50$, and dilute to one litre with distilled water.

Urease solution $-5 \mathrm{mg}$ of urease (from jack beans, type S) with $50 \%$ glycerol.

Working reagent for urea determination-Mix together $3.0 \mathrm{mg}$ of $\mathrm{NADH}, 18 \mathrm{mg}$ of adenosine-5diphosphate, $0.5 \mathrm{ml}$ of urease, and $0.05 \mathrm{ml}$ of glutamate dehydrogenase $(1200 \mathrm{U} / \mathrm{ml} 50 \%$ glycerol $)$ with $12 \mathrm{ml}$ of phosphate buffer containing 2oxoglutaric acid sodium salt.

Urea standard solution-Dissolve $21.42 \mathrm{mg}$ of urea with $100 \mathrm{ml}$ of distilled water.

\section{Procedure}

Each disc was placed in a test tube containing $0.15 \mathrm{ml}$ of glycine buffer and $0.05 \mathrm{ml} \mathrm{MnCl}_{2}$, and this mixture was activated at $37^{\circ} \mathrm{C}$ for 30 minutes. Next, $0.1 \mathrm{ml}$ of arginine solution was added and the mixture was incubated for 10 minutes. The reaction was stopped by adding $0.2 \mathrm{ml} \mathrm{HClO}_{4}(0.33 \mathrm{~mol} / \mathrm{l})$. For the blanks, arginine was added after $\mathrm{HClO}_{4}$. The mixture was centrifuged for 10 minutes at $3500 \mathrm{rpm}$. The urea concentration in the supernatant was measured with a centrifugal analyser, CentifiChem 400 . The analyser pipette was programmed for $5 \mu$ l of sample, $50 \mu \mathrm{l}$ of diluent water, and $350 \mu \mathrm{l}$ of reagent. After a lag period of one minute, the rate of decrease of absorbance at $340 \mathrm{~nm}$ was measured for one minute at $30^{\circ} \mathrm{C}$ and compared with that of the $3.57 \mathrm{mmol} / \mathrm{l}$ of urea standard solution. The cyanmethaemoglobin method was used for $\mathrm{Hb}$ determination. A disc was placed in $5 \mathrm{ml}$ of the reagent and shaken slowly for $\mathbf{4 0}$ minutes, the absorbance at $540 \mathrm{~nm}$ was then measured.

\section{Calculation}

$\left(\mathrm{U}_{\mathrm{s}}-\mathrm{U}_{\mathrm{B}}\right) \times 0.5 \times 10^{-3} \times \mathrm{Hb}(\mathrm{g})^{-1} \mathrm{IU} / \mathrm{g} \cdot \mathrm{Hb} \mathrm{U}_{\mathrm{s}}$ and $U_{B}$ are urea concentrations in the sample and the blank, respectively. One unit is the activity producing $1 \mu \mathrm{mol}$ urea for one minute at $37^{\circ} \mathrm{C}$. The activity is expressed in units per gram of $\mathrm{Hb}$.

The reproducibility and linearity of the method and the influence of the storage condition on arginase activity were studied.

\section{OTHER CLINICAL TESTS}

Lead concentrations in blood and urine were measured by anodic stripping voltammetry after the samples had been dried and ashed at $450^{\circ} \mathrm{C} .{ }^{10}$ Urine $\delta$-aminolaevulinic acid was measured by the method of Tomokuni and Ogata. ${ }^{11}$ Urine coproporphyrin was measured by the method of Sano and Granick. ${ }^{12}$ GOT, GPT, and albumin in serum were measured by the Reitman-Frankel method and the BCG method using an automated analyser (Hitachi, Ltd, Japan).

\section{Results}

Within-run precision studies showed a $4.09 \%$ coefficient of variation $(n=10)$. Arginase activity showed linearity up to $180 \mathrm{IU} / \mathrm{g} \cdot \mathrm{Hb}$ and no change in activity at room temperature $\left(25^{\circ} \mathrm{C}\right)$ for one week.

The percentage of the relative cumulative frequency of erythrocyte arginase activity in $\mathbf{4 5}$ control workers not exposed to lead was plotted on normal probability paper (fig 1). The distribution was of a normal type and the mean arginase activity of erythrocytes was $44.6 \pm 11.6 \mathrm{IU} / \mathrm{g} \cdot \mathrm{Hb}$. The 49 men occupationally exposed to lead had an activity of 62.9 $\pm 14.4 \mathrm{IU} / \mathrm{g} \cdot \mathrm{Hb}$, the difference in the mean activity between the two groups was significant $(p<0.001)$.

Table 1 shows the data of lead indicator tests with lead-exposed and lead-unexposed workers. In all tests the values in the lead-exposed group were from three to eightfold higher than those in the controls. The correlation between blood lead and lead indicators was studied and SE, SP, and V in each test were calculated, fixing the basic value of blood lead as $\mathbf{4 0}$ $\mu \mathrm{g} / 100 \mathrm{~g}$.

Figure 2 shows the correlation between blood lead 


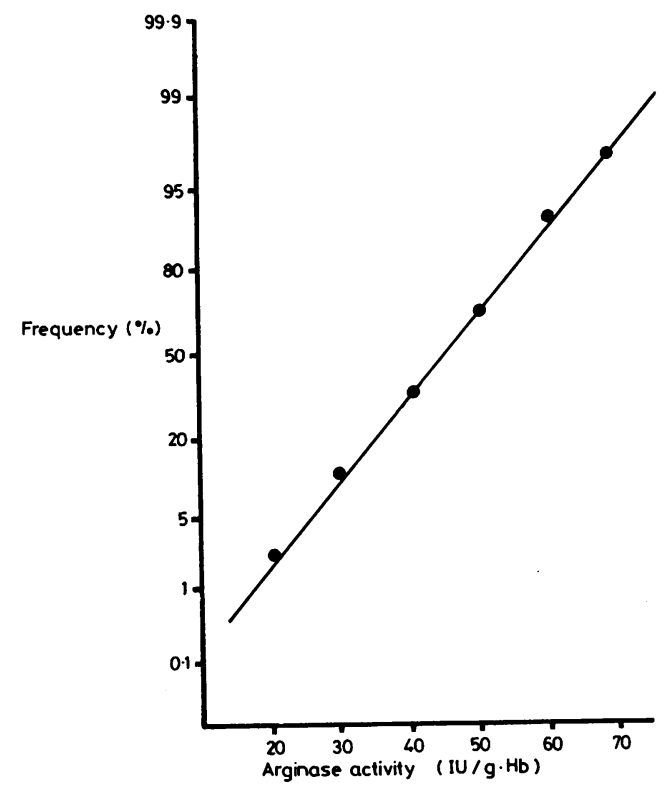

Fig 1 Relative accumulation frequency of erythrocyte arginase activity in workers not exposed to lead.

Table 1 Results from lead indicator tests with lead-exposed subjects and controls

\begin{tabular}{lllrl}
\hline No of subjects & $\begin{array}{l}\text { Lead workers } \\
(n=49)\end{array}$ & \multicolumn{2}{c}{$\begin{array}{l}\text { Controls } \\
(n=45)\end{array}$} \\
\cline { 2 - 5 } & $G M$ & $D F$ & $G M$ & $D F$ \\
\hline Blood lead $(\mu \mathrm{g} / 100 \mathrm{~g})$ & 33.0 & $1.5^{* * *}$ & 7.9 & 1.4 \\
Urine lead $(\mu \mathrm{g} / \mathrm{l})$ & 86.2 & $2.6^{* * *}$ & $10 \cdot 8$ & 1.4 \\
Urine $\delta$-ALA $(\mathrm{mg} / \mathrm{dl})$ & 6.0 & $0.032^{* * *}$ & $2 \cdot 2$ & $0 \cdot 013$ \\
Urine coproporphyrin $(\mu \mathrm{g} / \mathrm{l})$ & 48.1 & $3 \cdot 7^{* * *}$ & $12 \cdot 3$ & $1 \cdot 8$ \\
\hline
\end{tabular}

ALA $=\delta$-aminolaevulinic acid.

${ }_{* * *}$ Significant difference at $\mathrm{p}<0 \cdot 001$.

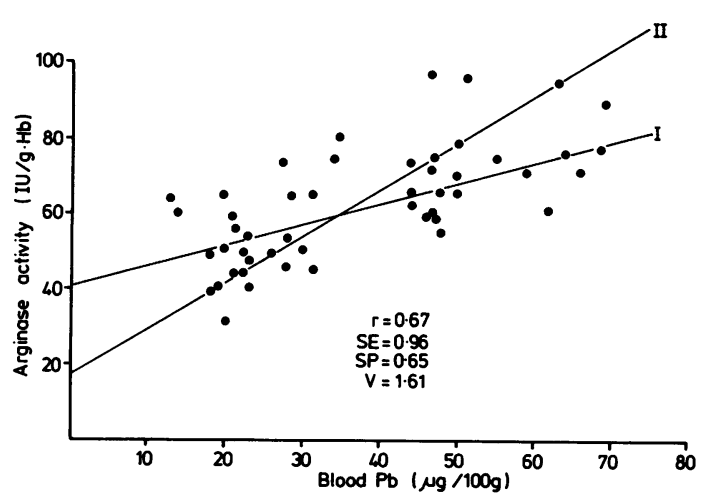

Fig 2 Correlation between blood lead and erythrocyte arginase. I $; Y=0.55 X+40, I I ; X=0.81 Y-13$.

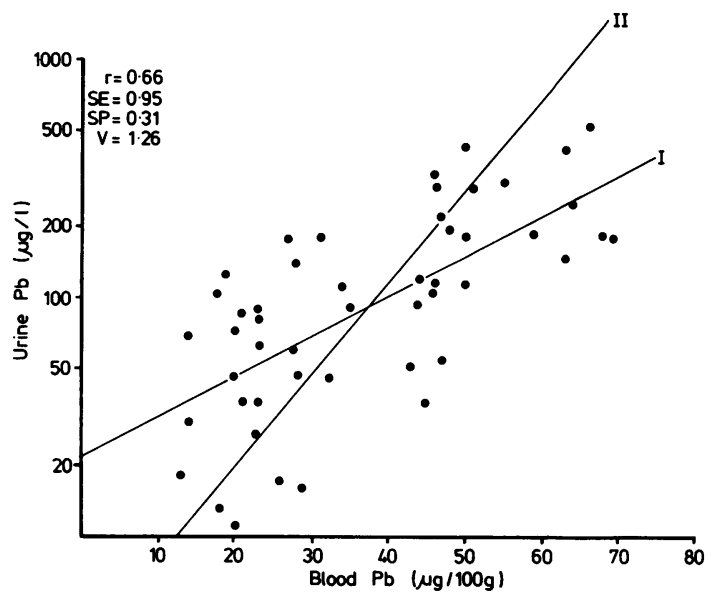

Fig 3 Correlation between blood lead and urine lead. $I ; \log Y=0.017 X+1.3, I I ; X=25.9 \log Y-14$.

and erythrocyte arginase. The coefficient of correlation was significant at $r=0.67(p<0.001)$. When $56 \cdot 2$ (mean $+1 \mathrm{SD}) \mathrm{IU} / \mathrm{g} \cdot \mathrm{Hb}$ of erythrocyte arginase activity was set as the screening value in fig $2, \mathrm{SE}$ and $S P$ were 0.96 and 0.65 . Therefore $V$ equalled 1.61 $(\mathrm{SE}+\mathrm{SP})$. Figure 3 shows the correlation between blood lead and urine lead. The coefficient of correlation was $r=0.66(p<0.001)$. When $40 \mu \mathrm{g} / \mathrm{l}$ of urine lead concentration was set as the screening value in fig $3, V$ was calculated to be 1.26 because SE and SP were 0.95 and 0.31 . Though SE of urine lead and erythrocyte arginase had the same value, SP and V of urine lead were less than those of arginase.

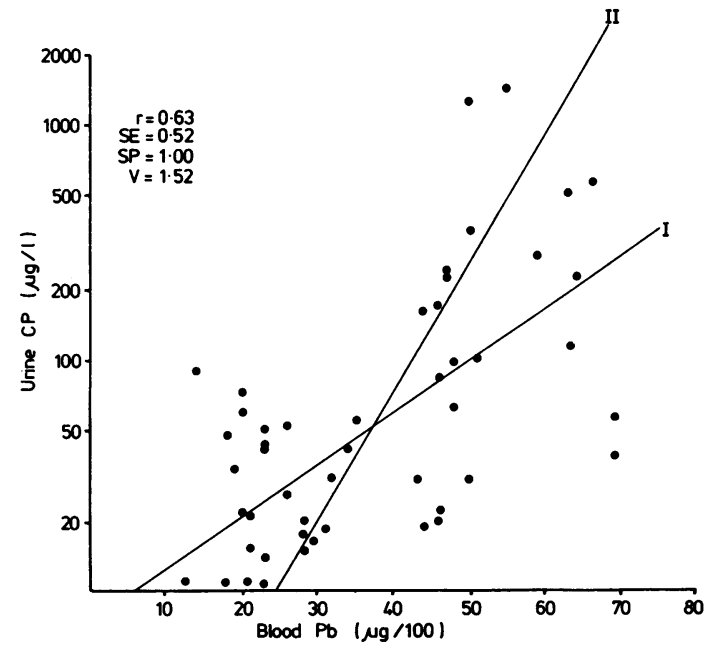

Fig 4 Correlation between blood lead and urine coproporphyrin. $I ; \log Y=0.022 X+0.89, I I ; X=$ $18.0 \log Y+6 \cdot 30$. 


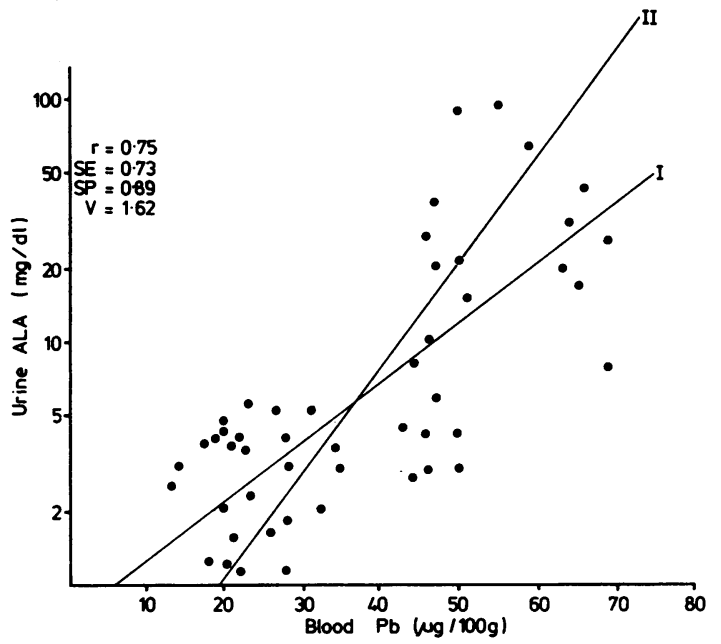

Fig 5 Correlation between blood lead and urine $\delta$-aminolaevulinic acid. $I ; \log Y=0.025 X-0.14$, $I I ; X=22.9 \log Y+19.5$.

Table 2 Coefficients of correlation between erythrocyte arginase and lead indicator tests and liver function tests in 49 lead-exposed subjects

\begin{tabular}{|c|c|}
\hline & $r$ \\
\hline $\begin{array}{l}\text { Blood lead } \\
\text { Urine lead } \\
\text { Urine coproporphyrin } \\
\text { Urine } \delta \text {-ALA } \\
\text { Serum GOT } \\
\text { Serum GPT } \\
\text { Serum albumin }\end{array}$ & $\begin{array}{l}0.67^{* * *} \\
0.58 * * * \\
0.57^{* * *} \\
0.61^{* * *} \\
0.087 \\
-0.019 \\
-0.082\end{array}$ \\
\hline
\end{tabular}

ALA $=\delta$-aminolaevulinic acid.

${ }_{* * *}$ Significant difference at $\mathrm{p}<0 \cdot 001$.

Figure 4 shows that the coefficent of correlation between blood lead and urine coproporphyrin was $r=0.63(p<0.001)$. When $100 \mu \mathrm{g} / 1$ of coproporphyrin was set as the screening.value, SE, SP, and V were $0 \cdot 52,1 \cdot 00$, and 1.52 , respectively. Though SE and $\mathrm{V}$ of $\mathrm{CP}$ were less than those of arginase, SP was better than that of arginase. Figure 5 shows the case of urine $\delta$-aminolaevulinic acid (ALA-U). The coefficient of correlation between blood lead and ALA$\mathrm{U}$ was the highest, $\mathrm{r}=\mathbf{0} \cdot \mathbf{7 5}$. When $5 \mathrm{mg} / \mathrm{dl}$ of ALA-U was set as the screening value, SE, SP, and $V$ were $0 \cdot 73,0.89$, and 1.62 , respectively. The V of ALA-U was almost the same as that of erythrocyte arginase.

Table 2 shows the coefficients of correlation between erythrocyte arginase and lead indicators and liver function tests. The highest correlation was found between erythrocyte arginase and blood lead. The degree of correlation with erythrocyte arginase was blood lead > ALA-U > urine lead > copropor- phyrin. No correlation was found between erythrocyte arginase and liver function tests such as GOT, GPT, and albumin in serum.

\section{Discussion}

Tests of urine lead, urine coproporphyrin, and ALA$U$ have been traditionally used to evaluate lead toxicosis and lead exposure. ${ }^{13-15}$ In these tests the screening values are set in relation to the basic value of blood lead. ${ }^{16} 17$ This paper compares the usefulness of the erythrocyte arginase test with other lead indicator tests.

The degree of correlation with blood lead was ALA-U $>$ erythrocyte arginase $>$ urine lead $>$ urine coproporphyrin. The coefficient of correlation between blood lead and ALA-U was high, $r=0.75$. When $40 \mu \mathrm{g} / 100 \mathrm{~g}$ of blood lead concentration was fixed as the basic value and $5 \mathrm{mg} / \mathrm{dl}$ of ALA-U was set as the screening value, SE and SP were 0.73 and 0.89 . Therefore this showed that ALA-U is an efficient indicator for lead exposure because $\mathrm{V}=1.62$ (SE + SP) (fig 5). The coefficient of correlation between blood lead and erythrocyte arginase was good, $r=$ $0.67(p<0.001)$. The mean arginase activity and SD in controls were $44.6 \pm 11.6 \mathrm{IU} / \mathrm{g} \cdot \mathrm{Hb}$. If the screening value was set as the mean arginase activity plus 2 SD it was calculated to be $67 \cdot 8 \mathrm{IU} / \mathrm{g} \cdot \mathrm{Hb}$. In this case SE, SP, and V were $0 \cdot 61,0 \cdot 88$, and $1 \cdot 49$, respectively. The SE and $V$ in this case were less than those of ALA-U. When the mean arginase activity plus $1 \mathrm{SD}$ $(56 \cdot 2 \mathrm{IU} / \mathrm{g} \cdot \mathrm{Hb})$ was set as the screening value for lead exposure, however, SE, SP, and V were $0.96,0.65$, and 1.61 , respectively. In this case, $S E$ of the arginase test was higher than that of the ALA-U test. Though there was a $4 \%$ probability of overlooking abnormal activity of erythrocyte arginase in a group with blood lead above $40 \mu \mathrm{g} / 100 \mathrm{~g}$, the probability of overlooking an abnormal value of ALA-U was $26 \%$.

In the relation between urine coproporphyrin and erythrocyte arginase, SE of the erythrocyte arginase test $(0.96)$ was higher than that of the urine coproporphyrin test $(0.52)$. But SP of urine coproporphyrin (1.00) was higher than that of the arginase test $(0 \cdot 65)$. Therefore, erythrocyte arginase is more efficient for screening for lead exposure than urine coproporphyrin. By comparison with urine lead, SP and V of the arginase test were higher than those of urine lead though SE in the two tests were the same. The degree of correlation with erythrocyte arginase was blood lead $>$ ALA-U $>$ urine lead $>$ urine coproporphyrin (table 2), which shows that erythrocyte arginase activity reflects well the dose-response effects of lead in the human body.

The serum arginase concentration is reported to be useful as the basis of a liver function test.$^{18}$ Bremner $e t$ 
$a l^{19}$ reported that plasma arginase activities in sheep increased with liver damage caused by copper intoxication. As erythrocyte arginase showed no correlation with GOT, GPT, and albumin in serum, it has no relation with liver diseases.

Determination of erythrocyte arginase activity by our method is rapid. Also, dried blood spots are easy to prepare and transport. As the erythrocyte arginase concentration reflects the reaction of the human body against lead, it may be efficiently used in screening for lead exposure. We suggest that $56 \cdot 2$ $\mathrm{IU} / \mathrm{g} \cdot \mathrm{Hb}$ of erythrocyte arginase activity be used as the screening value of lead exposure.

\section{References}

${ }^{1}$ Roholt OA, Greenberg DM. Liver arginase. I Effect of pH on kinetics of manganese-activated enzyme. Arch Biochem Biophys 1956;62:454-70.

2 Terheggen HG, Lowenthal A, Lavinha F, Colombo JP. Familial hyperargininaemia. Arch Dis Child 1975;50:57-62.

${ }^{3}$ Cederbaum SD, Shaw KNF, Valente M. Hyperargininaemia. J Pediatr 1977;90:569-73.

${ }^{4}$ Reynold J, Follett JH, Valentine WN. The arginase activity of erythrocytes and leukocytes with particular reference to pernicious anemia and thalassemia major. J Lab Clin Med 1957;50:78-92.

${ }^{5}$ Nishibe H, Yamagata K, Gotoh H. A case of sideroblastic anemia associated with marked elevation of erythrocytic arginase activity. Scand J Haematol 1975;15:17-21.
${ }^{6}$ Ugarte G, Pino ME, Peirano P, Marusić E. Serum arginase activity in subjects with hepatocellular damage. J Lab Clin Med 1960;55:522-9.

' Pelikan V, Kalab M, Tichy J. Determination of arginase activity in blood in epidemic hepatitis. Clin Chim Acta 1964;9:141-7.

${ }^{8}$ Chmielnicka J, Szumska EK, Szymanska JA. Arginase and kallikrein activities as biochemical indices of occupational exposure to lead. Br J Ind Med 1981;38:175-8.

${ }^{9}$ Zielhuis RL, Verberk MM. Validity of biological tests in epidemiological toxicology. International Archiv für Arbeitzmedizin 1974;32:167-90.

${ }^{10}$ Karai I, Fukumoto K, Horiguchi S. Improvement in the atomic absorption determination of lead in blood. J Appl Toxicol $1981 ; 6: 295-6$.

${ }^{11}$ Tomokuni K, Ogata M. Simple method for determination of urinary $\delta$-aminolevulinic acid as an index of lead exposure. Clin Chem 1972;18:1534-6.

${ }^{12}$ Sano S, Granick S. Mitochondrial coproporphynogen oxidase and protoporphyrin formation. J Biol Chem 1961;236:1173-80.

${ }^{13}$ Pán AYS. Lead levels in saliva and in blood. J Toxicol Environ Health 1981;17:273-80.

${ }^{14}$ Alessio L, Foa V. Human biological monitoring of industrial chemicals-4. Inorganic lead. Luxembourg: Commission of the European Communities, Health and Safety Directorate, 1980:57.

is Waldron HA, Stöfen D. Subclinical lead poisoning. London: Academic Press, 1974.

${ }^{16}$ Yamada Y, Kido T, Okada A, Nogawa K, Kobayashi E. Studies on the biological effects of low level lead exposure. Jpn J Ind Health 1981;23:260-9.

${ }^{17}$ Kehoe RA. Standards for the prevention of occupational lead poisoning. Arch Environ Health 1971;23:245-8.

${ }^{18}$ Forsell OM, Palva IP. Determination of arginase in serum. Scand J Clin Lab Invest 1961;13:131-3.

${ }^{19}$ Bremner I, Young BW, Mills CF. Protective effect of zinc supplementation against copper toxicosis in sheep. $\mathrm{Br} J$ Nutr 1976;36:551-61. 